\title{
Next Generation Sequencing of 502 Lifestyle and Nutrition related Genetic Polymorphisms reveals Independent Loci for Low Serum 25-hydroxyvitamin D Levels among Adult Respondents of the 2013 Philippine National Nutrition Survey*
}

\author{
Mark Pretzel Zumaraga, Mae Anne Concepcion, Charmaine Duante, Marietta Rodriguez \\ Department of Science and Technology - Food and Nutrition Research Institute, Bicutan, Taguig City, Philippines
}

\begin{abstract}
Objective. The study determined the relationship of serum vitamin D levels and 502 lifestyle and nutrition related genetic polymorphisms among adult respondents of the 2013 Philippine National Nutrition Survey (NNS).

Methodology. A total of 1,160 adult respondents of the 2013 NNS living in the National Capital Region, Philippines were enrolled. Of the 1,160 sequenced samples, 833 passed the stringent quality control based on multiple parameters and were used for further analysis. Total serum 25-hydroxyvitamin D [25(OH)D] was determined using electro-chemiluminescence binding assay method. Genomic DNA was used for targeted next generation sequencing of 502 lifestyle and nutrition related polymorphisms. Analysis of variance, followed by Tukey post hoc analysis, was employed to compare $25(\mathrm{OH}) \mathrm{D}$ serum levels across genotypes.

Results. Of the study participants, $56 \%$ was classified as having low serum 25(OH)D. The lower serum 25(OH)D was observed in the following gene/genotypes: KNG1 rs11924390 T/T; ANKH rs2454873 G/G; NPFFR2 rs4129733 T/G; SH2B1 rs4788102 G/A; RAP1A rs494453 T/T and CRHBP rs7728378 T/C. These genes were previously associated to the risk of osteoporosis, obesity, type 2 diabetes mellitus, and stress response.

Conclusion. Large-scale analysis of genes has shown great utility in the discovery of genetic factors that play a role in vitamin D nutrition. Interestingly, loci found in this Filipino population cohort were mostly independent from the canonical vitamin D synthesis and metabolism pathways. Understanding how genetic variations interact with nutrition and lifestyle may aid in the prevention of diseases through screening and identification of susceptible patients who would not benefit from regular supplementation with vitamin D because of genetic alterations and may also be used as basis for future development of functional food enriched with vitamin D.
\end{abstract}

Key words: Vitamin D, nutrition, nutrigenetics

\section{INTRODUCTION}

Vitamin D deficiency (VDD) is a widespread disorder across all age groups around the world. In fact, in addition to infectious diseases and malnutrition, it is among the most prevalent health disorders in recent years. ${ }^{1}$ The high prevalence of VDD in a number of countries exists despite the fact that a large number of these countries lie in zones that have sufficient sunlight for vitamin D synthesis including Malaysia, Indonesia and the Philippines. ${ }^{2}$ In the Philippines, of the five areas covered during the 2013 National Nutrition Survey (NNS), the highest proportion of deficient and insufficient levels in the country was found in Benguet at $60.3 \%$ and lowest in Cagayan at 19.5\%.
Generally, there were more deficient and insufficient levels among the females compared to the males. Particularly, the lowest mean vitamin D levels were found among women of reproductive age group, 20-39 years old $(63.5 \pm 1.7 \mathrm{nmol} / \mathrm{L})^{3}$

Historically, VDD has been linked to skeletal diseases, including calcium, phosphorus, and bone metabolism, osteoporosis, fractures, muscle strength, and falls. In the 2000s, growing scientific attention turned to non-skeletal chronic diseases as VDD has been linked to cancer, cardiovascular diseases, metabolic disorders, autoimmune diseases, as well as infectious diseases such as respiratory tract infections. ${ }^{4}$ Recently, vitamin $\mathrm{D}$ has been
ISSN 0857-1074 (Print) | eISSN 2308-118x (Online)

Printed in the Philippines

Copyright (C) 2021 by Zumaraga et al.

Received: July 22, 2020. Accepted: January 31, 2021.

Published online first: April 26, 2021.

https://doi.org/10.15605/jafes.036.01.08
Corresponding author: Mark Pretzel P. Zumaraga, RCh, MSc

Science Research Specialist II, Department of Science and Technology-Food and

Nutrition Research Institute, FNRI Building, DOST Compound,

General Santos Avenue, Bicutan, Taguig City, Philippines 1631

Tel. No.: +632-8372071 local 2299

Fax No.: $+632-8372934$

E-mail: mpzumaraga@yahoo.com

ORCiD: https://orcid.org/0000-0001-5598-8456

* Presented during the simultaneous research oral presentation of the $20^{\text {th }}$ ASEAN Federation of Endocrine Societies Congress 2019 on November $21-23$ at the Philippine International Convention Center Manila, Philippines using the title "Nutrigenomics: A Study on Vitamin D and Lifestyle-Related Genes in Adults." 
discovered to induce the production of cathelicidins and defensins, which are natural anti-microbials, and has been proposed to prevent and treat coronavirus disease 2019 (COVID-19). ${ }^{5}$

External exposures (sunlight, diet, and vitamin D supplements) are chief determinants of circulating $25(\mathrm{OH})$ $\mathrm{D}$, the established marker of vitamin D status. However, with several genes controlling pathways that synthesize, transport, and degrade forms of vitamin D, individual genetic variations may also play a role in individual (and potentially population) differences in vitamin D status. Due to inter-individual genetic variation, people who are exposed to a high amount of sunlight or taking high dose of vitamin D supplementation may also suffer from low serum $25(\mathrm{OH}) \mathrm{D}$ level. With vitamin D implicated in a wide range of health issues from rickets to cancer and respiratory infections, a fuller understanding of the determinants of vitamin $\mathrm{D}$ status is needed and must include consideration of inherited characteristics. ${ }^{6}$

Recent genome-wide association studies (GWASs) of serum $25(\mathrm{OH}) \mathrm{D}$ that covered more than 79,366 individuals of European ancestry have identified at least six common genetic variants (minor allele frequency $>0.05$ ). These polymorphisms are found in the following genes: (1) the GC (the vitamin D-binding protein gene), (2) the DHCR7/ NADSYN1 region (DHCR7 is involved in a conversion of a 25(OH)D precursor molecule to cholesterol), (3) CYP2R1 and (4) CYP24A1 genes (which encode enzymes involved in $25(\mathrm{OH}) \mathrm{D}$ metabolism), as well as (5) SEC23A (Sec23 homolog A, coat protein complex II component involved in endoplasmic reticulum (ER)-Golgi protein trafficking, and (6) AMDHD1 (amidohydrolase domain containing 1) an enzyme involved in the histidine, lysine, phenylalanine, tyrosine, proline, and tryptophan catabolic pathway. Revez et al., further identified 143 independent loci for $25(\mathrm{OH}) \mathrm{D}$ in genes involved in lipid metabolism, dermal tissue properties and conjugation of 25(OH)D. ${ }^{8}$ Manousaki et al., sought to investigate the phenotypic variance as explained by the genetic variants. One implication of their findings is that the potential genetic influence for vitamin $\mathrm{D}$ is instrumenting more than the vitamin D pathway, hence, future studies must focus on interrogating genetic regions (1) not directly involved in 25(OH)D biology; and (2) related to environmental confounders that influence $25(\mathrm{OH}) \mathrm{D}$ levels. Additionally, most GWAs have predominantly been focused on European populations, which provide limited information on the usefulness of discovered variants in populations of non- European ancestry.

Although the investigations of whole exomes or even genomes is increasing, sequencing of a specific set of genes (targeted resequencing) is important for research and clinical settings due to its lower cost, maximum coverage of target regions, and more accessible data interpretation. ${ }^{9}$ Our study determined the putative relationship of serum $25(\mathrm{OH}) \mathrm{D}$ levels with several variations in lifestyle related genes among adult respondents, age 20 years old and above, of the 2013 NNS by targeted resequencing.

This study can be used as basis for a future genetic panel specific to the Filipino population that could assist clinicians in screening and identifying patients who would not benefit from the usual supplementation with vitamin
D because of genetic alterations. Our results might also aid in promoting awareness in the scientific community of researchers to identify the involved mechanisms. ${ }^{9}$

\section{METHODOLOGY}

Study Subject Ascertainment and Ethical Consideration This is a sub-study of the vitamin D survey component of the 2013 Philippine NNS. The statistical design used in the vitamin D survey component was a multi-staged stratified sampling design. The first stage of the sampling was the selection of the Primary Sampling Unit (PSU) which consisted of one barangay or a contiguous barangay with at least 500 households. The second stage was the selection of the Enumeration Area (EA) which consisted of a contiguous area in a barangay with 150-200 households and the last stage was the selection of households in the sampled EA that served as the ultimate sampling unit. The survey lasted from June 19 to December 4, 2013 and continued on February 16 to April 15, 2014. For this substudy, a total of 1,160 adult Filipino respondents from the National Capital Region (NCR) of the 2013 NNS, aged 20-years and above were included. The protocol (code FIERC-2017-002) was approval by the DOST-FNRI Ethics Review Committee for implementation on 31 March 2017.

All the respondents provided written informed consent approving the general research use of their respective specimens for biochemical and DNA analyses, as well as lifestyle information including age, medical history of falls during the past 12 months, use of calcium and vitamin D supplements, calcium intake, serum $25(\mathrm{OH}) \mathrm{D}$, reproductive characteristics, lifestyle behavior and previous history of fragility fracture. Respondents were excluded if they met one of the following (1) female, pregnant and lactating at the time data were collected; and/or (2) did not have complete data on the study variables of interests.

\section{Study Variables}

From the household face-to-face interview, the following information on age, sex, race/ethnicity (self-identified), smoking habits, sleeping hours, previous history of fracture (hip and other parts) were collected. Individual food consumption was obtained using a two-day nonconsecutive 24- hour Food Recall, one during a weekday and one during a weekend. Individual Dietary Evaluation System (IDES) was used to determine the nutrient content of food items accurately recalled and consumed.

From the examination data, body mass index (BMI) was calculated as weight in kilograms divided by height in meters squared. The waist circumference was measured as the perimeter or distance around the natural waist (midway between the lowest rib and the tip of the hip bone) or a measure of the distance around the narrowest portion of the trunk. The tape measure was placed at the midpoint and the respondent was asked to breathe normally; measurement was taken at the end of normal expiration. The hip circumference was measured as the distance around the largest area of the hips, usually the largest part of the buttocks or the greater trochanter. Smoking status was classified as never, current, or former smoker. Blood pressure level was measured using a nonmercurial sphygmomanometer and stethoscope, following standard procedures. ${ }^{10}$ Measurements were taken twice. 
Total serum 25(OH)D was contracted to an ISO/IEC 15189 accredited laboratory and was determined using the electro-chemiluminescence binding assay method. ${ }^{11}$ Briefly, $15 \mathrm{uL}$ of serum sample were incubated with a pretreatment reagent for nine minutes to aid release of bound vitamin D 25(OH)D from its Vitamin D binding protein. The sample was further incubated with a recombinant ruthenium-labeled VDBP to form a complex of Vitamin D (25OH) and ruthenylated-VDBP. Then, with the addition of a biotinylated vitamin $\mathrm{D}$ a complex consisting of the ruthenium-labeled VDBP and the biotinylated vitamin $\mathrm{D}$ was formed. The entire complex now became bound to the solid phase via interaction of biotin and streptavidin-coated microparticles, which are captured on the surface of the electrode. Voltage was applied to the electrode causing chemiluminescent emission that can be quantified by a photomultiplier. Results were determined via an instrument-specific calibration curve, which is generated by 2-point calibration and a calibration master curve provided via the reagent barcode. The method is standardized against LC-MS/MS, which in turn is traceable to National Institute of Standards and Technology (NIST). The measuring range of the method used is $3.00-70.0 \mathrm{ng} / \mathrm{mL}$ (7.50-175 nmol/L), with sensitivity of $4.01 \mathrm{ng} / \mathrm{mL}(10.0 \mathrm{nmol} / \mathrm{L})$ (CV $18.5 \%)$ and repeatability and intermediate reproducibility values of $\leq 6.5 \%$ and $\leq 11.5 \%$, respectively (https:// www.accessdata.fda.gov/cdrh_docs/reviews/K162840. pdf, accessed on November 3, 2020). All blood collections were done inside rooms to avoid exposure of the collected specimen to direct sunlight. In the field, serum was kept frozen in freezers or in ice chests with dry ice. Blood samples in the frozen state were transported to the Biochemical Laboratory (BL) of DOST-FNRI.. These were kept in $-80^{\circ} \mathrm{C}$ freezers until laboratory analysis was conducted.

\section{Development of SNP panel}

A total of 502 variations in lifestyle and diet related genes were selected from literature and the Human Gene Mutation Database (HGMD; http://www.biobaseinternational.com/product/hgmd). Ion Ampliseq Designer was used to design the Ampliseq Custom Amplicon panel (both Thermo Fisher Scientific, USA) using 275 bp amplicons with UCSC hg19 (https://genome.ucsc.edu/) as the reference genome. Target regions for resequencing comprised the whole exon, exon-intron boundary, and regulatory region (10 kb upstream from the transcription start site) of genes of interest, accounting for a total of $108,670 \mathrm{bp}$.

\section{Targeted Resequencing of the Nutrigenomics Related} Genes

Targeted next generation-sequencing (NGS) remains a popular approach that allows to sequence specific areas of the genome (i.e., selected lifestyle-related genes), for a more rapid and cost-effective mutation analysis than the whole genome sequencing. Briefly, DNA was sequenced using the Ion Proton Next Generation Sequencing or NGS (Invitrogen Life Technologies, USA) according to manufacturer's instructions. For the targeted amplification of 502-genes associated with nutrition-related diseases, the custom Ion Ampliseq ${ }^{\mathrm{TM}}$ (Invitrogen Life Technologies, USA), was used. Diluted barcode adapter mix including Ion Xpress ${ }^{\mathrm{TM}}$ Barcode Adapter and Ion P1 adaptor were ligated to the end of the digested amplicons with ligase provided in the kit. Adaptor ligated amplicon libraries were purified and subsequently quantified by Quant-iT ${ }^{\mathrm{TM}}$ dsDNA HS Assay (Invitrogen, Life Technologies, USA) and Qubit ${ }^{\circledR}$ Fluorometer (Invitrogen, Life Technologies, USA) according to the manufacturers' procedures. After quantification, each amplicon library was equalized and pooled. A template was prepared using the Ion PGM 200 Xpress Template Kit (Invitrogen Life Technologies, USA) and sequencing was performed using the Ion Sequencing kit version 2.0 on an Ion 318 Chip. Preliminary data analysis was done using the Ampliseq ${ }^{\mathrm{TM}}$ Variant Caller plug-in within the Ion Torrent Suite software (Invitrogen Life Technologies, USA). Sequencing and downstream bioinformatics analysis were performed at the Philippine Genome Center, University of the Philippines, Diliman, Quezon City.

\section{Bioinformatics and Mutation Calling}

Sequencing reads were aligned and filtered using Torrent Suite v3.6.2 (Invitrogen Life Technologies, USA) and the Ampliseq Custom Panel manifest. Variants were annotated and filtered using Torrent Suite v3.6.2. Variant filters were established using a sample set with known mutations and filter settings verified using blinded samples. Annotations were done on variants with quality score $>100$, read depth $\geq 30$, mutant allele frequency of $\geq 15 \%$. Filtered variants were visualized in genomic context using IGV (Interactive Genomics Viewer: http:// www. broadinstitute.org/igv/) to exclude sequencing artifacts. There were a total of seven independent sequencing runs conducted to analyze all the samples. Sequencing information of each run is shown in Table 1 .

\section{Statistical Analysis}

Statistical analysis was performed using the Stata software (version 13.0; Statacorp LLC). Data normality was analyzed using the Kolmogorov-Smirnov test. Normally distributed data were compared using the unpaired $t$ test and expressed as means \pm SDs. Non-normally distributed data are expressed as medians and IQRs. Betweengroup comparisons were assessed using the MannWhitney $U$ test. Pearson's chi-square test was performed to analyze the categorical data. One-way ANOVA, followed

Table 1. Sequencing information of the target regions of the tested samples

\begin{tabular}{|c|c|c|c|c|c|c|}
\hline Run No. & $\begin{array}{c}\text { No. of samples } \\
\text { analyzed per run (n) }\end{array}$ & $\begin{array}{c}\text { Total effective read } \\
\text { base number }(\mathrm{Kb})\end{array}$ & $\begin{array}{c}\text { Percent read base } \\
\text { number on target (\%) }\end{array}$ & $\begin{array}{l}\text { Ave. sequencing } \\
\text { depth on target }\end{array}$ & $\begin{array}{c}\text { Percent } \\
\text { uniformity }(\%)\end{array}$ & $\begin{array}{c}\text { No. of variants } \\
\text { determined (Ave.) }\end{array}$ \\
\hline 1 & 57 & 119.9 & 88.1 & 173.4 & 92.2 & 297 \\
\hline 2 & 49 & 59.1 & 91.1 & 67.9 & 81.5 & 255 \\
\hline 3 & 77 & 379.9 & 96.4 & 593.3 & 96.6 & 325 \\
\hline 4 & 88 & 334.0 & 95.8 & 513.1 & 96.2 & 326 \\
\hline 5 & 88 & 532.0 & 92.5 & 790.3 & 96.0 & 327 \\
\hline 6 & 203 & 150.2 & 92.0 & 201.9 & 95.0 & 319 \\
\hline 7 & 271 & 242.9 & 95.9 & 381.1 & 95.6 & 322 \\
\hline
\end{tabular}


by Tukey post hoc test for multiple comparisons, was used to find association between serum 25(OH)D concentration and genotypes. P-value of less than 0.05 was considered significant. Participants were stratified into two groups according to their vitamin D status: 1 ) serum $25(\mathrm{OH}) \mathrm{D}<75$ $\mathrm{nmol} / \mathrm{L}$, defined as low serum vitamin $\mathrm{D}$, and 2) serum $25(\mathrm{OH}) \mathrm{D} \geq 75 \mathrm{nmol} / \mathrm{L}$, indicating a normal serum vitamin D status. ${ }^{12}$

\section{RESULTS}

A total of 1,160 adult respondents of the 2013 NNS adult participated in the study. Of them, 833 passed our inclusion criteria (See Materials and Methods). Four hundred sixty-six (56\%) subjects were classified as low (deficient and insufficient) serum $25(\mathrm{OH}) \mathrm{D}$ concentration $(<75 \mathrm{nmol} / \mathrm{mL})$ and 367 subjects had normal serum $25(\mathrm{OH})$ $\mathrm{D}(\geq 75 \mathrm{nmol} / \mathrm{L})$. Table 2 shows the socio-demographic and anthropometric profiles of study participants, delineating study subjects with low versus normal serum vitamin D concentration. Notably, we found no significant differences in terms of age in years, BMI, waist and hip circumferences and waist-hip ratio between the two groups. Most of the participants with low vitamin D were female $(p<0.01)$.

Diverse environmental factors regulate $25(\mathrm{OH}) \mathrm{D}$ metabolism, among which are diet, sun exposure, pollution, and infection. The majority of these factors exert their effects on $25(\mathrm{OH}) \mathrm{D}$ concentration by regulating the expression of vitamin D receptor (VDR) protein. ${ }^{13}$ Table 3 presents

Table 2. Socio-demographic and anthropometric profile of study participants

\begin{tabular}{lccc}
\hline & $\begin{array}{c}\text { Low vit. D } \\
(<75 \text { nmol/L) } \\
(\mathbf{n = 4 6 6 )}\end{array}$ & $\begin{array}{c}\text { Normal vit. D } \\
(\geq 75 \text { nmol/L) } \\
(\mathbf{n}=367)\end{array}$ & ${ }^{*}$ p-value \\
\hline Age in years (SD) & $41(16)$ & $47(15)$ & 0.1455 \\
\hline $\begin{array}{l}\text { Sex (n, \%) } \\
\text { Male }\end{array}$ & $148(32)$ & $220(60)$ & $<0.0001^{*}$ \\
$\quad$ Female & $318(68)$ & $147(40)$ & \\
\hline $\begin{array}{l}\text { Ave Body mass index in } \\
\text { kg/m }{ }^{2} \text { SD) }\end{array}$ & $24.0(4.4)$ & $23.7(4.2)$ & 0.3203 \\
\hline $\begin{array}{l}\text { Ave waist circumference in } \\
\text { cm (SD) }\end{array}$ & $81.5(12.1)$ & $81.8(11.8)$ & 0.1564 \\
\hline $\begin{array}{l}\text { Ave hip circumference in } \\
\text { cm (SD) }\end{array}$ & $91.6(8.8)$ & $90.1(8.9)$ & 0.2737 \\
\hline Ave waist-to-hip ratio (SD) & $0.89(0.08)$ & $0.91(0.08)$ & 0.2633 \\
\hline * Pearson's Chi-squared test $p$-value $\leq 0.05$ is considered significant
\end{tabular}

Table 3. Median nutrient intake of low serum vitamin D vs normal serum vitamin $D$ between study subjects

\begin{tabular}{|c|c|c|c|}
\hline Nutrient intake & $\begin{array}{c}\text { Low vit. D } \\
(<75 \mathrm{nmol} / \mathrm{L}) \\
(\mathrm{n}=466)\end{array}$ & $\begin{array}{c}\text { Normal vit. D } \\
(\geq 75 \mathrm{nmol} / \mathrm{L}) \\
(\mathrm{n}=367)\end{array}$ & ${ }^{*} p$-value \\
\hline Energy (median, IQR) & $1,639.8(882.2)$ & $1,617.7(810.7)$ & 0.309 \\
\hline Protein (median, IQR) & $53.1(28.2)$ & $54.5(29.2)$ & 0.921 \\
\hline Cholesterol (median, IQR) & $268.2(147.9)$ & $271.6(147.5)$ & 0.546 \\
\hline Fat (median, IQR) & $28.3(32.2)$ & $29.6(26.4)$ & 0.477 \\
\hline Vitamin A (median, IQR) & $203.6(300.1)$ & 215.5 (306.9) & 0.921 \\
\hline Thiamin (median, IQR) & $0.7(0.6)$ & $0.7(0.5)$ & 0.103 \\
\hline Riboflavin (median, IQR) & $0.6(0.4)$ & $0.6(0.4)$ & 0.309 \\
\hline Niacin (median, IQR) & $17.5(9.1)$ & $18.3(8.8)$ & 0.685 \\
\hline Vitamin C (median, IQR) & $14.7(28.2)$ & $15.3(31.5)$ & 0.836 \\
\hline Iron (median, IQR) & $7.8(5.1)$ & $8.7(5.8)$ & 0.186 \\
\hline Calcium (median, IQR) & $253.1(199.5)$ & $269.7(224.5)$ & 0.309 \\
\hline
\end{tabular}

the dietary profile of study participants living in the National Capital Region, Philippines.

Many clinical observations also raised the possibility of a link between vitamin D and risk factors of known metabolic diseases. ${ }^{14}$ Table 4 shows the clinical information of study subjects with low and normal vitamin D serum. There were no statistically different means found in systolic, diastolic and sleeping hours, indicating both groups are demographically equivalent. Most participants in both groups were found to be non-smokers, no history of fracture at the hip and other body parts.

Being reliant on an a priori hypotheses for gene selection, this study was limited to known gene candidates that may potentially show variation in serum $25(\mathrm{OH}) \mathrm{D}$ concentration. Table 5 shows list of genetic variations that were found to have statistically significant difference in serum $25(\mathrm{OH}) \mathrm{D}$ concentration across genotypes at $\mathrm{p}$-value $<0.05$. Our study team call these nutrigenetic (coined from nutrition and genetics) markers of vitamin $\mathrm{D}$ nutrition because they are highly sensitive to serum $25(\mathrm{OH}) \mathrm{D}$ levels. Indication of lower serum $25(\mathrm{OH}) \mathrm{D}$ was observed in the following gene/genotypes ( $<75 \mathrm{nmol} / \mathrm{L}$, see Table 4$)$ : KNG1 rs11924390 T/T; ANKH rs2454873 G/G; NPFFR2 rs4129733 T/G; SH2B1 rs4788102 G/A; RAP1A rs494453 T/T and CRHBP rs7728378 T/C. Supplementing with vitamin D or increasing sun exposure could be helpful for people with these genetic variations. ${ }^{15}$

\section{DISCUSSION}

Due to the fact that the vitamin D receptor (VDR), the single known regulatory mediator of hormonal vitamin $\mathrm{D}$ in higher vertebrates, is expressed in almost every tissue and cell throughout the human body, there have been extensive investigations on potential extra-skeletal effects of vitamin D. ${ }^{24}$ This study determined the relationship of serum $25(\mathrm{OH}) \mathrm{D}$ concentration with selected lifestyle disease related genes among 1,160 individual NCR respondents of the 2013 Philippine NNS. Of the 1,160 sequenced samples, 833 passed the stringent QC based on multiple parameters and were used for further analysis. S1 Table describes details of the candidate gene regions selected for targeted resequencing. A summary of high-quality variants analyzed for their distribution and association with serum $25(\mathrm{OH}) \mathrm{D}$ is provided in S2 Table.

Table 4. Clinical and risk indicators of overall health between low and normal serum vitamin D study participants

\begin{tabular}{|c|c|c|c|}
\hline & $\begin{array}{c}\text { Low vit. D } \\
(<75 \mathrm{nmol} / \mathrm{L}) \\
(\mathrm{n}=466)\end{array}$ & $\begin{array}{c}\text { Normal vit. D } \\
(\geq 75 \mathrm{nmol} / \mathrm{L}) \\
(\mathrm{n}=367)\end{array}$ & $p$-value \\
\hline $\begin{array}{l}\text { Average systolic, } \mathrm{mmHg} \\
\text { (SD) }\end{array}$ & $118.5(20)$ & $121.3(20)$ & 0.1546 \\
\hline $\begin{array}{l}\text { Average diastolic, } \mathrm{mmHg} \\
\text { (SD) }\end{array}$ & $76.7(12)$ & $78.2(11)$ & 0.2201 \\
\hline Smoking $(n, \%)$ & & & 0.01694 \\
\hline Non-smokers & $308(37)$ & $209(25)$ & \\
\hline Current smokers & $92(11)$ & $100(12)$ & \\
\hline Former smokers & $66(8)$ & $58(7)$ & \\
\hline Sleeping hours $(\mathrm{h})$ & $7.3(1.4)$ & $7.7(8.5)$ & 0.177 \\
\hline Previous hip fracture $(n, \%)$ & $2(0.4)$ & $4(1)$ & 0.262902 \\
\hline $\begin{array}{l}\text { Previous fracture, other } \\
\text { body parts }(n, \%)\end{array}$ & $18(3.9)$ & $18(4.9)$ & 0.462817 \\
\hline
\end{tabular}


Table 5. Nutrigenetic markers found to have significantly different 25(OH)D3 concentration across genotypes

\begin{tabular}{|c|c|c|c|c|c|c|}
\hline Gene (dbSNP) & Function & $\begin{array}{c}\text { Disease pathology/ } \\
\text { phenotype }\end{array}$ & Genotype & $\begin{array}{c}\text { No. of study } \\
\text { subjects }(N=833)\end{array}$ & $\begin{array}{c}\text { Ave. serum vit. D } \\
\text { concentration (SD) }\end{array}$ & ${ }^{*} p$-value \\
\hline \multirow[t]{3}{*}{${ }^{\text {aKNG1 (rs11924390) }}$} & upstream & adiponectin levels ${ }^{16}$ & $T / T$ & 451 & $72.4(27)^{a, b}$ & 0.0042 \\
\hline & & & $\mathrm{T} / \mathrm{C}$ & 256 & $78.4(29)^{b}$ & \\
\hline & & & $\mathrm{C} / \mathrm{C}$ & 126 & $79.6(32)^{a}$ & \\
\hline \multirow[t]{3}{*}{${ }^{\mathrm{b} A N K H}$ (rs2454873) } & intron & Bone mass & $\mathrm{G} / \mathrm{G}$ & 451 & $73.0(27)^{\mathrm{a}}$ & 0.0377 \\
\hline & & and geometry ${ }^{17}$ & $\mathrm{G} / \mathrm{A}$ & 315 & $78.0(31)^{a}$ & \\
\hline & & & $\mathrm{A} / \mathrm{A}$ & 67 & $78.4(26)$ & \\
\hline \multirow[t]{3}{*}{ cNPFFR2 (rs4129733) } & intron & Obesity $^{18}$ & $T / T$ & 557 & $76.6(28)^{a}$ & 0.0325 \\
\hline & & & $\mathrm{T} / \mathrm{G}$ & 236 & $71.7(29)^{a}$ & \\
\hline & & & G/G & 40 & $78.3(25)$ & \\
\hline \multirow{3}{*}{ dSH2B1 (rs4788102) } & & & $\mathrm{G} / \mathrm{G}$ & 586 & $77.0(28)^{\mathrm{a}}$ & 0.0094 \\
\hline & intron & Obesity $^{19,20,21}$ & G/A & 220 & $70.4(26)^{a}$ & \\
\hline & & & $\mathrm{A} / \mathrm{A}$ & 27 & $79.6(39)$ & \\
\hline \multirow{3}{*}{ eRAP1A (rs494453) } & & & $T / T$ & 195 & $71.4(27)^{a}$ & 0.0277 \\
\hline & intron & Osteoporosis ${ }^{22}$ & $\mathrm{~T} / \mathrm{C}$ & 442 & $75.4(28)^{a}$ & \\
\hline & & & $\mathrm{C} / \mathrm{C}$ & 196 & $79.1(31)$ & \\
\hline \multirow[t]{3}{*}{${ }^{f} \mathrm{CRHBP}$ (rs7728378) } & intron & Stress response ${ }^{23}$ & $T / T$ & 174 & $79.0(32)^{a}$ & 0.0433 \\
\hline & & & $\mathrm{T} / \mathrm{C}$ & 396 & $72.9(27)^{\mathrm{a}}$ & \\
\hline & & & $\mathrm{C} / \mathrm{C}$ & 263 & $76.6(27)$ & \\
\hline \multicolumn{7}{|c|}{ 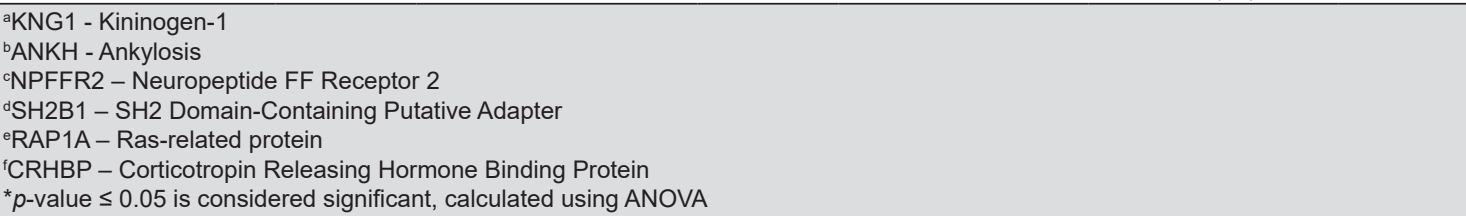 } \\
\hline
\end{tabular}

Of the study participants, $56 \%$ was classified as low serum $25(\mathrm{OH}) \mathrm{D}$. An individual's vitamin $\mathrm{D}$ stores are best reflected by serum $25(\mathrm{OH}) \mathrm{D}$ which is influenced by diet, age, BMI, sex, skin color, and numerous factors regulating exposure to ultraviolet $\mathrm{B}$ radiation. Comparing cases and controls, we found no differences in most of parameters tested in the study, including median nutrient consumption. The NCR is the financial, commercial and industrial center of the Philippines. However, in spite of its urbanized state, the region experiences the effects of the double burden of malnutrition in the form of undernutrition and over nutrition, affecting vulnerable population groups such as children and women (accessed at: https://www.nnc.gov.ph/2-uncategorised/244-ncrprofile; on July 20, 2020). Among the Philippine regions, NCR had the lowest intake of cereals and cereal products (298 grams) particularly rice and rice products (260 grams) and corn and corn products ( 3 grams), but registered the highest intake in other cereal products (35 grams), which include breads and noodles. A high intake of fish, meat and poultry (246 grams), particularly meat and meat products (96 grams) and poultry (53 grams), was also noted. Other food groups highly consumed in the region were whole milk (46 grams) and vitamin C-rich fruits (13 grams) and beverages (36 grams). However, vegetables, particularly green, leafy, and yellow vegetables (29 grams), and condiments and spices (7 grams) were minimally consumed. ${ }^{25}$ Despite evidence for association between $25(\mathrm{OH}) \mathrm{D}$ concentration against carbohydrate, protein, and calcium dietary intake, the observed difference did not vary between $25(\mathrm{OH}) \mathrm{D}$ classification.

However, it is noteworthy that vitamin D status in females was significantly worse than in males in this group of study subjects $(p<0.0001)$. Natural differences in terms of the amount of subcutaneous fat between males and females could be one of main reasons for the gender difference in serum vitamin D levels, where women have more subcutaneous fat than men. As vitamin D is fat-soluble and the subcutaneous adipose tissue can store large amounts of it, the greater average amount of subcutaneous fat in women takes up more vitamin $\mathrm{D}$ molecules leading to fewer vitamin D molecules entering the blood circulation in women than in men. ${ }^{26}$

Traditional twin studies have shown that between the range $50 \%-80 \%$ serum $25(\mathrm{OH}) \mathrm{D}$ variability is explained by genetic factors, indicating that it is a highly heritable trait. In fact, our data discovered at least six genetic variations putatively associated with abnormal serum 25(OH)D concentrations $(p<0.05)$. These genes were previously associated to the risk of osteoporosis, type 2 diabetes mellitus, obesity, and stress response. ${ }^{16-23}$ Individualized approach, such as vitamin D dietary intervention and/or sun exposure, based on genetic make-up may be helpful for individuals with these genetic variation. ${ }^{15}$ Moreover, a particular gene hotspot for serum $25(\mathrm{OH}) \mathrm{D}$ concentration, recently discovered through a large-scale GWAS metaanalysis in 2020, was replicated in the present study, the NPFFR2. ${ }^{27}$ The Neuropeptide FF (NPFF; with the sequence FLFQPQRF) belongs to the RF-amide peptide family and was first isolated from bovine brain by virtue of the shared N-terminal sequence, RF-NH2. ${ }^{18}$ NPFF is ubiquitously expressed in the central nervous system with highest expression in the hypothalamus, posterior pituitary and spinal cord. There are two known NPFF cognate receptors, NPFFR1 (GRP147) and NPFFR2 (GPR74). NPFFR2, a G-protein receptor that binds neuropeptides, is highly expressed in pain-processing regions such as spinal dorsal horn, thalamus and dorsal raphe nucleus. ${ }^{18}$ Dahlman et al., have typed four SNPs at this locus and showed that one particular haplotype was protective against obesity. ${ }^{28}$ The protective haplotype was associated with higher adipocyte lipid mobilization. NPFFR2 is also known to be closely linked to the GC/VDBP during the whole evolution of vertebrates. VDBP, or Vitamin D binding protein, plays 
an important role in the transport and metabolism of vitamin D. In 2019, the first case of a large deletion in the coding portion of the VDBP gene (and adjacent NPFFR2 gene) in a single family was reported. The proband had normal calcium, phosphate and parathyroid hormone levels. When provided with vitamin $\mathrm{D}$ supplementation due to very low levels of $25(\mathrm{OH}) \mathrm{D}$, the patient was not responsive even to massive doses of vitamin $\mathrm{D}$ (oral or parenteral). The homozygous partial NPFFR2 deletion is of uncertain significance at that time, since the gene has yet to be associated with human disease. Nevertheless, as confirmed from previous GWAS for vitamin levels, the putative mechanism with regard to the causal relationship of genetic variation of NPFRR2 and obesity as mediated by individual's serum vitamin D status, is worth investigating in future studies.

Other gene targets identified were found in gene sets and pathways mostly independent from the canonical vitamin D synthesis and metabolism pathways. This is similar to the discoveries of Manousaki and Revez et al., in 2020, where both have established new and novel biological pathways outside the vitamin D pathways, that influence $25(\mathrm{OH}) \mathrm{D}$ levels. This discovery further demonstrated that the $25(\mathrm{OH})$ $\mathrm{D}$ metabolite is moderately polygenic. Identification of genetic regions not directly involved in $25(\mathrm{OH}) \mathrm{D}$ biology and related to environmental confounders that influence $25(\mathrm{OH}) \mathrm{D}$ levels has provided a deeper understanding of the genetic determinants contributing to variation in circulating vitamin $\mathrm{D}$ levels that may allow better genomic prediction of vitamin $\mathrm{D}$ levels and provide insights into biological mechanisms ${ }^{27}$ especially that two of the discovered genetic variants, namely the KNG1 (rs11924390) and SH2B1 (rs4788102), have been previously isolated and identified to be present among Filipino population cohort. ${ }^{16,21}$

A significant limitation continues to center on the interpretation and parsing of detected variants based on clinical utility. However, as comprehensive genomic variation in vitamin $\mathrm{D}$ metabolism continues to be documented, greater insight into the spectrum of variants underlying the phenotypic heterogeneity commonly observed in vitamin D deficiency subtypes has been gained. Although the sample sizes are the largest to date, they are small, especially for the Filipino population cohort $(\mathrm{N}=833){ }^{29}$ Therefore, our results require replications in other vitamin D Filipino cohorts. We did not evaluate possible associations between SNP genotypes and vitamin D metabolite ratios, which may be considered as a further limitation. Furthermore, results of this study are not fully maximized because data on amount of exposure to sunlight, including time of day and duration of exposure were not collected. Data on vitamin D intake was not calculated because there is no vitamin $\mathrm{D}$ in the Philippine Food Composition Table at the time the survey was completed. Other factors such as use of sunblock, occupation and supplements were not interpreted in this paper because a previous study showed that these factors were not strong predictors of vitamin D status among Filipinos unlike gender, age and location. ${ }^{30}$ Finally, in the absence of clear evidence of epistasis (i.e., the interaction between two or more genes to control a single phenotype), our findings suggest that a number of genetic and nongenetic risk factors (sex) may independently (and additively) contribute to the risk of vitamin $\mathrm{D}$ deficiency in this group of Filipino study participants of NNS.
There are some major advantages to restricting the genetic analysis to a limited set of genes: targeted enrichment and subsequent resequencing provides a superior quality of representation and a much higher read depth than whole genome sequencing. The result is promising that high accuracy could be obtained if the read depth is $>200$ coverage. It will provide a useful guidance for the future local genotyping studies. Moreover, clinical implementation of targeted Ampliseq ${ }^{\circledR}$ NGS has the potential to diagnose individuals with vitamin $\mathrm{D}$ deficiency with a high degree of speed and accuracy and at lower cost than either Sanger sequencing or whole exome sequencing. Secondly, most genetic studies of vitamin D status have been performed in European white descent cohorts. VDD does not appear exclusively in white individuals, and studies limited to a single race could miss VDD risk loci unique to different ancestries, at least among South East Asian-descendants.

Finally, to the best of our knowledge, this is the first Philippine pilot study on vitamin D status that encompasses all the available genetic evidence associated with noncommunicable diseases, such as obesity and diabetes, given that previous work has been limited to describe a few genes involved in vitamin D pathways or the common genes identified by GWAS. $12,25,26$

An improved understanding of the genetic determinants of $25(\mathrm{OH}) \mathrm{D}$ will contribute in precise determination of the role of vitamin D in the etiology of complex diseases, such as musculoskeletal disorders, autoimmune disease, including multiple sclerosis, type 2 diabetes mellitus, obesity and even cancer. For example, four separate gene-disease studies have supported a protective effect of vitamin D against multiple sclerosis, and these results had clinical implications, reflected in recent clinical care guidelines for the use of vitamin D in preventing multiple sclerosis in those at risk, published by the MS Society of Canada. Moreover, in view of the important role in vitamin D metabolism of the genes identified, consideration should be given to develop a genetic panel that could be used in the clinical setting for those individuals or populations particularly vulnerable to vitamin D deficiency. In addition, the panel would be beneficial for patients with proven VDD or insufficiency who do not respond to appropriate doses of vitamin D supplementation, subjects who are vitamin $\mathrm{D}$ deficient in spite of enough sunlight exposure or who live in countries at an adequate latitude, and those with sufficient ingestion of vitamin $\mathrm{D}$ rich foods.

\section{CONCLUSION AND RECOMMENDATION}

Large-scale analysis of genes associated with lifestyle disease and other determinants of overall health have shown great utility in the discovery of genes and polymorphisms that play a role in vitamin $\mathrm{D}$ nutrition. Our data discovered at least six genetic variations that showed a statistically significant difference in serum vitamin $\mathrm{D}$ concentration across genotypes. These genes were previously shown to have contributed to disease pathologies such as type 2 diabetes mellitus, obesity, osteoporosis, and stress response. Although the exact molecular mechanisms of the discovered nutrigenetic markers remain to be determined, our study provides evidence that polymorphisms in lifestyle related genes play a role in vitamin D deficiency susceptibility. Identifying 
genetic variants affecting functional status of vitamin D is important for understanding the role of this regulatory hormone in the prevention of certain diet related diseases such as type 2 diabetes mellitus, obesity, osteoporosis, and micronutrient deficiency and imbalance.

Taken together, this pilot study has provided additional evidence-based information on the putative contribution of genetic variants to optimizing intake recommendations, focusing on the Filipino population. There are many risk factors that have been reported to be associated with vitamin $\mathrm{D}$ deficiency, and genetic factors are among them. Further study is needed to explore the possibility of the involvement of genetic variations as risk factor for vitamin $\mathrm{D}$ deficiency and related diseases in the population. It is envisioned that understanding how genetic variations interact with environmental factors, especially nutrition, may hold the key to better prevention and management of diseases, particularly nutrition related diseases.

Moreover, data that may be generated from a national nutrition survey, where DOST-FNRI is the lead implementing agency, can provide an excellent opportunity to test the association of vitamin D deficiency with multiple health outcomes in a large, admixed sample of the general population.

The correction of low vitamin D concentrations can happen only if some or all of the following are implemented: the encouragement of safe, moderate exposure of skin to ultraviolet light; appropriate increases in food fortification with vitamin $\mathrm{D}$; and the provision of vitamin $\mathrm{D}$ in diet to the right person-individual and patient, at the right dose, at the right time.

\section{Acknowledgments}

This study has been conducted as a collaborative study of the Nutrigenomics Unit, Nutritional Assessment and Monitoring Division (NAMD) and the Philippine Genome Center (PGC). National Nutrition Survey (NNS) data was taken from NAMD under the supervision of Imelda Angeles-Agdeppa, $\mathrm{PhD}$ and genetic analysis was performed at PGC. The authors gratefully acknowledge the participation of NNS volunteers. The authors would also like to thank Cynthia P. Saloma, PhD of PGC and Celeste Tanchoco, DrPH for generously sharing their expertise in the conduct of the massively parallel next generation sequencing and calcium and vitamin D dietary assessment, respectively.

\section{Statement of Authorship}

All authors certified fulfillment of ICMJE authorship criteria.

\section{Author Disclosure}

The authors declared no conflict of interest.

\section{Funding Source}

None.

\section{References}

1. Arabi A, El Rassi R, El-Haji Fuleihan, G. Hypovitaminosis D in developing countries-prevalence, risk factors and outcomes. Nat Rev Endocrinol. 2010;6(10):550-61. PMID: 20852586. https://doi.org/ 10.1038/nrendo.2010.146.

2. Kruger MC, Schollum LM, Kuhn-Sherlock B, et al. The effect of a fortified milk drink on vitamin D status and bone turnover in postmenopausal women from South East Asia. Bone. 2010;46(3):759-67. PMID: 19895912. https://doi.org/10.1016/j.bone.2009.10.036.

3. Food and Nutrition Research Institute-Department of Science and Technology. Philippine Nutrition Facts and Figures 2013: Biochemical Survey, 2015
4. Alshahrani F, Aljohani N. Vitamin D: Deficiency, sufficiency and toxicity. Nutrients. 2013:5(9):3605-16. PMID: 24067388. PMCID: PMC3798924. https://doi.org/10.3390/nu5093605.

5. Grant WB, Lahore H, McDonnell SL, et al. Evidence that vitamin D supplementation could reduce risk of influenza and covid-19 infections and deaths. Nutrients. 2020;12(4):988. PMID: 32252338. PMCID: PMC7231123. https://doi.org/10.3390/nu12040988.

6. Signorello LB, Shi J, Cai QC, et al. Common variation in vitamin D pathway genes predicts circulating 25-hydroxyvitamin D levels among African Americans. PLoS One. 2011;(12):e28623. PMID: 22205958 PMCID: PMC3244405. https://doi.org/10.1371/journal.pone.0028623.

7. Jiang X, Kiel DP, Kraft P. The genetics of vitamin D. Bone. 2019;126:5977. PMID: 30316967. https://doi.org/10.1016/j.bone.2018.10.006.

8. Revez JA, Lin T, Qiao Z, et al. Genome-wide association study identifies 143 loci associated with 25 hydroxyvitamin D concentration. Nat. Commun. 2020;11(1):1647. PMID: 32242144. PMCID: PMC7118120. https://doi.org/10.1038/s41467-020-15421-7.

9. Sepulveda-Villegas M, Elizondo-Montemayor L, Trevino V. Identification and analysis of 35 genes associated with vitamin D deficiency: A systematic review to identify genetic variants. J Steroid Biochem Mol Biol. 2020;196:105516. PMID: 31678109. https://doi.org/ 10.1016/j.jsbmb.2019.105516.

10. Pickering TG, Hall JE, Appel LJ, et al. Recommendations for blood pressure measurement in humans and experimental animals: Part 1: Blood pressure measurement in humans: A statement for professionals from the Subcommittee of Professional and Public Education of the American Heart Association Council on High Blood Pressure. Circulation. 2005;111(5):697-716. PMID: 15699287. https:// doi.org/10.1161/01.CIR.0000154900.76284.F6.

11. Vesper HW, Sempos CT. Vitamin D standardization program. Clin Chem. 2011;57(10 Suppl 1):A177. Retrieved from https://meeting aacc.org/-/media/Files/Meetings-and-Events/Annual-Meeting/2011/ AACC_11_FullAbstract.pdf?la=en\&hash=A762BB9A047239D 3DB858A1DE4D0C21C4C378A7E.

12. Nimitphong H, Holick MF. Vitamin D status and sun exposure in southeast Asia. Dermatoendocrinol. 2013·5(1):34-7. PMID: 24494040. PMCID: PMC3897596. https://doi.org/10.4161/derm.24054.

13. Zella LA, Kim S, Shevde NK, Pike JW. Enhancers located within two introns of the vitamin $\mathrm{d}$ receptor gene mediate transcriptiona autoregulation by 1,25-dihydroxyvitamin D 3. Mol Endocrinol. 2006;20(6):1231-47. PMID: 16497728. https://doi.org/10.1210/me. 2006-0015.

14. Grübler MR, März W, Pilz S, et al. Vitamin-D concentrations, cardiovascular risk and events - A review of epidemiological evidence. Rev Endocr Metab Disord. 2017;18(2):259-72. PMID: 28451877. https://doi.org/10.1007/s11154-017-9417-0.

15. Nissen J, Vogel U, Ravn-Haren G, et al. Common variants in CYP2R1 and GC genes are both determinants of serum 25-hydroxyvitamin D concentrations after UVB irradiation and after consumption of vitamin D3-fortified bread and milk during winter in Denmark. Am J Clin Nutr. 2015;101(1):218-27. PMID: 25527766. https://doi.org/ 10.3945/ajen.114.092148.

16. $\mathrm{Wu} Y, \mathrm{Li}_{\mathrm{Y}}$, Lange $\mathrm{EM}$, et al. Genome-wide association study for adiponectin levels in filipino women identifies $\mathrm{CDH} 13$ and a novel uncommon haplotype at KNG1-ADIPOQ. Hum Mol Genet 2010;19(24):4955-64. PMID: 20876611. PMCID: PMC2989895. https:// doi.org/10.1093/hmg/ddq423.

17. Kiel DP, Demissie S, Dupuis J, Lunetta KL, Murabito JM, Karasik D. Genome-wide association with bone mass and geometry in the Framingham Heart Study. BMC Med Genet. 2007;8 Suppl 1(Suppl 1):S14. PMID: 17903296. PMCID: PMC1995606. https:// doi.org/10.1186/1471-2350-8-S1-S14.

18. Hunt SC, Hasstedt SJ, Xin Y, et al. Polymorphisms in the NPY2R gene show significant associations with BMI that are additive to FTO, MC4R, and NPFFR2 gene effects. Obesity (Silver Spring). 2011;19(11): 2241-7. PMID: 21818152. PMCID: PMC3733173. https://doi.org/ 10.1038/oby. 2011.239.

19. Fu LW, Zhang MX, Wu LJ, Gao LW, Mi J. Gene-gene interaction on central obesity in school-aged children in China. Zhongzhua Liu Xing Bing Xue Za Zhi. 2017;38(7):883-8. PMID: 28738459. https://doi. org/10.3760/cma.j.issn.0254-6450.2017.07.007.

20. Rui L. SH2B1 regulation of energy balance, body weight, and glucose metabolism. World J Diabetes. 2014;5(4):511-26. PMID: 25126397. PMCID: PMC4127586. https://doi.org/10.4239/wjd.v5.i4.511.

21. Croteau-Chonka DC, Marvelle AF, Lange EM, et al. Genomewide association study of anthropometric traits and evidence of interactions with age and study year in Filipino women. Obesity. 2011;19(5): 1019-27. PMID: 20966902. PMCID: PMC3046220. https:// doi.org/10.1038/oby.2010.256

22. Hsu YH, Zillikens MC, Wilson SG, et al. An integration of genomewide association study and gene expression profiling to prioritize the discovery of novel susceptibility loci for osteoporosis-related traits. PLoS Genet. 2010;6(6):e1000977. PMID: 20548944. PMCID: PMC2883588. https://doi.org/10.1371/journal.pgen.1000977. 
23. Enoch MA, Shen PH, Ducci F, et al. Common genetic origins for EEG, alcoholism and anxiety: The role of CRH-BP. PLoS One. 2008;3(10):e3620. PMID: 18974851. PMCID: PMC2575401. https://doi. org/10.1371/journal.pone.0003620.

24. Trummer $\mathrm{O}$, Schweighofer $\mathrm{N}$, Haudum $\mathrm{CW}$, et al. Genetic components of 25-hydroxyvitamin D increase in three randomized controlled trials. J Clin Med. 2020;9(2):570. PMID: 32093012. PMCID: PMC7074051. https://doi.org/10.3390/jcm9020570.

25. Food and Nutrition Research Institute-Department of Science and Technology. Philippine Nutrition Facts and Figures 2013: Food Consumption Survey Title, 2015

26. Yan X, Zhang N, Cheng S, Wang Z, Oin Y. Gender differences in vitamin D status in China. Med Sci Monit. 2019;25:7094-9. PMID: 31541605. PMCID: PMC6767943. https://doi.org/10.12659/ MSM.916326.
27. Manousaki D, Mitchell R, Dudding T, et al. Genome-wide association study for vitamin D levels reveals 69 independent loci. Am J Hum Genet. 2020;106(3):327-37. PMID: 32059762. PMCID: PMC7058824. https://doi.org/10.1016/j.ajhg.2020.01.017.

28. Dahlman I, Dicker A, Jiao $\mathrm{H}$ et al A common haplotype in the G-protein-coupled receptor gene GPR74 is associated with leanness and increased lipolysis. Am J Hum Genet. 2007;80(6):1115-24 PMID: 17503329. PMCID: PMC1867099. https://doi.org/10.1086/518445.

29. Hong J, Hatchell KE, Bradfield JP, et al. Transethnic evaluation identifies low-frequency loci associated with 25-hydroxyvitamin D concentrations. J Clin Endocrinol Metab. 2018;103(4):1380-92. PMID: 29325163. PMCID: PMC6276579. https://doi.org/10.1210/jc.2017-01802

30. Angeles-Agdeppa I, Perlas LA, Capanzana, MV. Vitamin D status of Filipino adults: Evidence from the 8th National Nutrition Survey 2013. Malays J Nutr. 2018;24:395-406.

Authors are required to accomplish, sign and submit scanned copies of the JAFES Author Form consisting of: (1) Authorship Certification, that authors contributed substantially to the work, that the manuscript has been read and approved by all authors, and that the requirements for authorship have been met by each author; (2) the Author Declaration, that the article represents original material that is not being considered for publication or has not been published or accepted for publication elsewhere, that the article does not infringe or violate any copyrights or intellectual property rights, and that no references have been made to predatory/suspected predatory journals; (3) the Author Contribution Disclosure, which lists the specific contributions of authors; (4) the Author Publishing Agreement which retains author copyright, grants publishing and distribution rights to JAFES, and allows JAFES to apply and enforce an Attribution-Non-Commercial Creative Commons user license; and (5) the Conversion to Visual Abstracts ( ${ }^{*}$ optional for original articles only) to improve dissemination to practitioners and lay readers Authors are also required to accomplish, sign, and submit the signed ICMJE form for Disclosure of Potential Conflicts of Interest. For original articles, authors are required to submit a scanned copy of the Ethics Review Approval of their research as well as registration in trial registries as appropriate. For manuscripts reporting data from studies involving animals, authors are required to submit a scanned copy of the Institutional Animal Care and Use Committee approval. For Case Reports or Series, and Images in Endocrinology, consent forms, are required for the publication of information about patients; otherwise, appropriate ethical clearance has been obtained from the institutional review board. Articles and any other material published in the JAFES represent the work of the author(s) and should not be construed to reflect the opinions of the Editors or the Publisher.

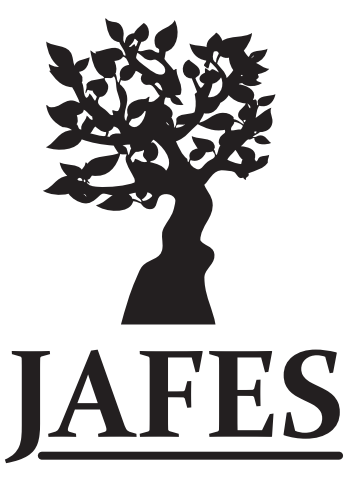

\section{Clinical controversies and disease updates are also welcome. Instructions to Authors available at www.ASEAN-endocrinejournal.org.}

